\title{
Study on Corrosion Resistance of Superhydrophobic Film Prepared on the Surface of 2024 Aluminum Alloy
}

\author{
Xiaokun $\mathrm{Li}^{1,2, *}$, Xin $\mathrm{Liu}^{3}$ \\ ${ }^{1}$ School of Environment Engineering, Yellow River Conservancy Technical Institute, Kaifeng 475004, \\ China \\ ${ }^{2}$ Henan Engineering Technology Research Center of Green Coating Materials, Kaifeng 475004, China \\ ${ }^{3}$ School of Environmental Science and Engineering, Suzhou University of Science and Technology, \\ Suzhou 215009, China \\ *E-mail: li kaifeng004@,163.com
}

Received: 8 October 2021 / Accepted: 18 November 2021 / Published: 5 January 2022

Superhydrophobic film was prepared on the surface of aluminum alloy by anodic oxidation, ammonium fluorotitanate sealing and perfluorooctanoic acid modification sequentially. The morphology and composition of the film were characterized and analyzed. Moreover, the surface wettability, stability and corrosion resistance of samples were tested. The results show that the density and corrosion resistance of porous anodic oxide film on aluminum alloy surface are improved after surface modification. After surface modification, the surface of anodic oxide film forms rough structure resulting in optimal superhydrophobicity performance with maximum droplet contact angle $155.6^{\circ}$. The superhydrophobic film has good corrosion resistance, while maintaining superhydrophobicity for a long time, which can effectively block the corrosive medium to inhibit the development of corrosion and provide stable corrosion protection for aluminum alloy.

Keywords: Superhydrophobic film; Corrosion resistance; Anodic oxidation; Sealing; Surface modification

\section{$\underline{\text { FULL TEXT }}$}

(C) 2022 The Authors. Published by ESG (www.electrochemsci.org). This article is an open access article distributed under the terms and conditions of the Creative Commons Attribution license (http://creativecommons.org/licenses/by/4.0/). 